\title{
Irrepressible pain treatment: Small Auto Emo Infusion and subcutaneous infiltrations of oxygen-ozone monitored with echography
}

\author{
Roberto Morello, Marina Piccoli \\ Oxygen-Ozone Therapy Scientific Society, Gorle (BG), Italy
}

\section{Abstract}

This is a case of an 82-year-old woman with a two year left coxalgia, following a complete hip prosthetic implant, treated with an oxygenozone therapy cycle ( $5 \mathrm{ng}$ subcutaneous infiltrations and $10 \mathrm{ng}$ small artery elasticity index).

\section{Case Report}

In 2014, an 86-year-old woman affected by left hip osteoarthritis (grade 3 of Kellgren and Lawrence system for classification of hip osteoarthritis) $)^{1,2}$ was treated with complete prosthetic implant of the hip.

During these two years, the patient suffered of a chronic hip drugresistant pain. She tried to assume non-steroidal anti-inflammatory drug (NSAID), opioid drugs, sedatives drugs without any satisfactory result.

In April 2016 she came to my ambulatory with an important hip pain, and an important functional limitation of the hip. In May 2016 she started an oxygen-ozone therapy cycle with Small Auto Emo Infusion and subcutaneous infiltrations in the cutaneous projection of the hip. In a one-month treatment, consisting in 3 Small Auto Emo Infusion and 8 subcutaneous infiltrations, pain symptoms disappeared and she had an important increase of the hip function.

Correspondence: Roberto Morello, Oxygen-Ozone Therapy Scientific Society, Via Roma 69, 24020, Gorle (BG), Italy

E-mail: dott.robertomorello@gmail.com

Key words: Echography; Power Doppler; Hip pain; Oxygen-ozone; Small Auto Emo Infusion.

Conflict of interest: the authors declare no potential conflict of interest.

Received for publication: 18 July 2016.

Accepted for publication: 28 August 2016.

CC Copyright R. Morello and M. Piccoli, 2016

Licensee PAGEPress, Italy

Ozone Therapy 2016; 1:6269

doi:10.4081/ozone.2016.6269

This article is distributed under the terms of the Creative Commons Attribution Noncommercial License (by-nc 4.0) which permits any noncommercial use, distribution, and reproduction in any medium, provided the original author(s) and source are credited.

\section{Discussion and Conclusions}

Thigh pain syndrom ${ }^{3}$ is a painful syndrome of the hip that can occur after hip replacement with complete prosthetic implant. This syndrome is characterized by chronic hip pain, both at rest and during walking, and an important articular limitation.

An 82-year-old woman came to my ambulatory in April 2016 suffering from a two years hip pain following surgery with a complete prosthetic implant of the hip for coxarthrosis. The patient also showed a passive range-of-motion (ROM) of the hip consisting in flection $30^{\circ}$, extension $3^{\circ}$, abduction $8^{\circ}$, adduction $5^{\circ}$, intra and extra rotation $5^{\circ}$. The patient also had pain, resistant to all drug treatment proposed (NSAID, opioid drugs, sedative drugs) during the whole day for two years, . She had a visual analogue scale (VAS) of $9 / 10$ and a numeric rating scale (NRS) of $9 / 10 .^{4}$ She also had an important hip discomfort studied by Lequesne index of the hip that showed a score of $18 / 24 .^{5-7}$

She brought a hip x-ray that showed a correct implant of the protesis and no significant bone signs. She also made an echography of the hip that showed an ileo psoas bursitis and nonspecific inflammatory signs of the periarticular tissues studied by power Doppler parameter (Figure $1 \mathrm{~A}, \mathrm{~B}){ }^{8}$

I decided to treat this pain with Small Auto Emo Infusion and subcutaneous infiltrations of oxygen-ozone $\left(\mathrm{O}_{2}-\mathrm{O}_{3}\right)$.

Small Auto Emo Infusion was given with a frequency of one each 10 days. I used $10 \mathrm{cc}$ of $\mathrm{O}_{2}-\mathrm{O}_{3}$ with a concentration of $10 \mathrm{ng}$ mixed with 10 cc of autologous venous blood. Subcutaneous infiltrations were administrated with a frequency of one each 4 days. I used $5 \mathrm{cc}$ of $\mathrm{O}_{2}-\mathrm{O}_{3}$ with a concentration of $5 \mathrm{ng}$ for each subcutaneous point treated. I treated the points of the cutaneous projection of the hip (proximal region of the thigh, anterior and posterior and the inguinal region).

After a one-month treatment we had incredible results in subjective symptoms studied by the VAS, NRS and Lequesne index and in objective tissue response studied by echography (Figure $1 \mathrm{C}, \mathrm{D}$ ).

VAS underwent to $2 / 10$, NRS underwent to $1 / 10$ and Lequesne index underwent to 7.5/24. She also referred to me a significant improvement of the quality of life. The echography showed a healing of the ileo psoas bursitis and a reduction of the periarticular inflammation showed by a modification of the power Doppler parameter.

The passive ROM of the hip also increased. She showed in fact flection $60^{\circ}$, extension $5^{\circ}$, abduction $25^{\circ}$, adduction $15^{\circ}$, intra and extra rotation $10^{\circ}$.

After this first phase of the treatment, the patient will return to my ambulatory once a month to have Small Auto Emo Infusion and subcutaneous infiltration with the same parameters to maintain these results and to give her a satisfying quality of life. 

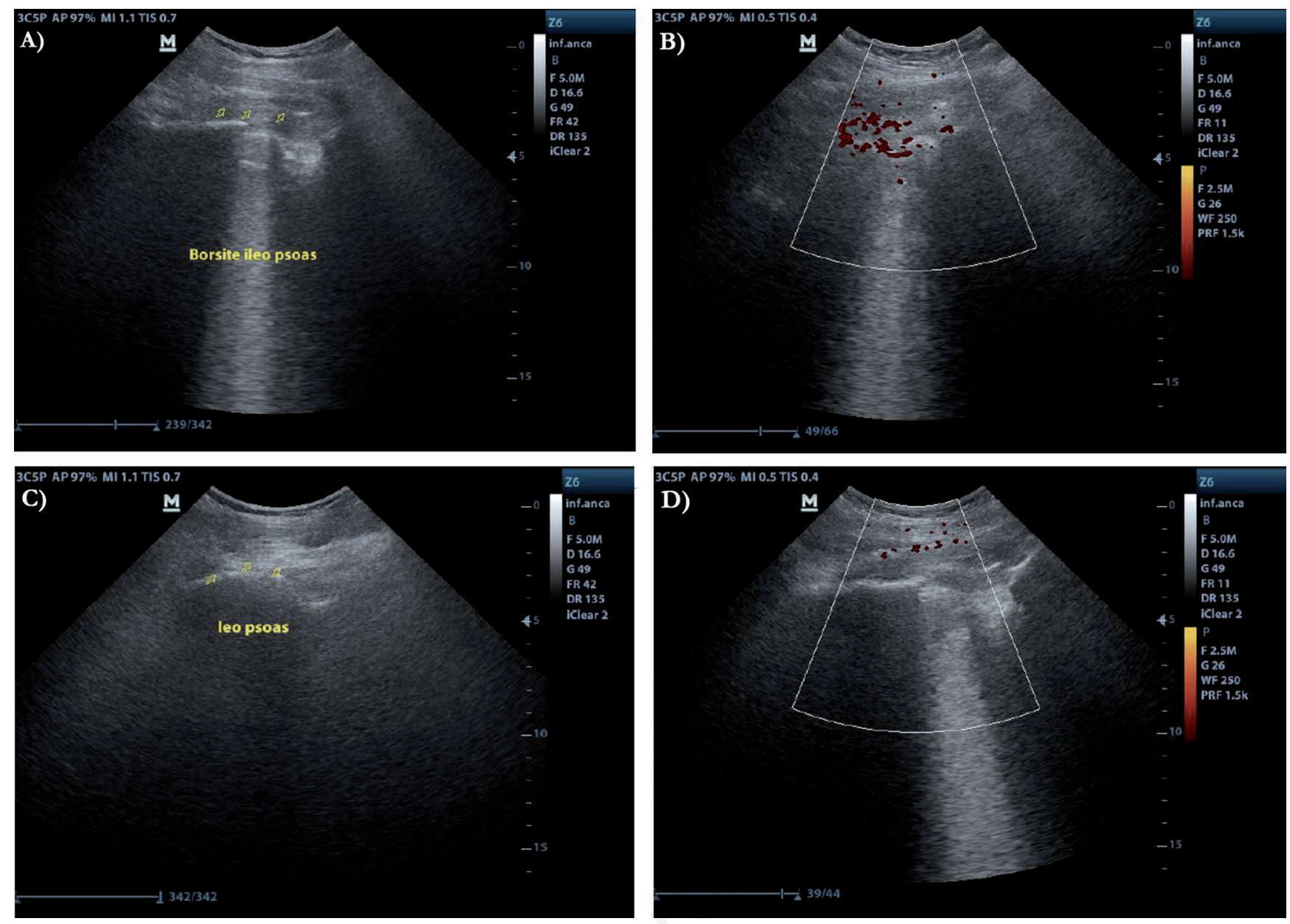

Figure 1. A) Ileo psoas bursitis; B) inflammatory signs with power Doppler; C) healing of the ileo psoas bursitis after one month treatment; D) decrease of the inflammatory signs with power Doppler after one month treatment.

\section{References}

1. Kellgren JH, Lawrence JS. Radiological assessment of osteo-arthrosis. Ann Rheum Dis 1957;16:494-502.

2. Altman R, Alacorn G, Appelrouth D, et al. The American College of Rheumatology criteria for the classification and reporting of osteoarthritis of the hip. Arthritis Rheum 1991;34:505-14.

3. Rispoli FP, Corolla FM, Mussner R. The use of low frequency pulsing electromagnetic fields in patients with painful hip prosthesis. J Bioelectricity 1988;7:181-7.
4. Scott J, Huskisson EC. Vertical or horizontal visual analogue scales. Ann Rheum Dis 1979;38:560.

5. Lequesne MG, Mery C, Samson M, Gerard P. Indexes of severity for osteoarthritis of the hip and knee. Validation-value in comparison with other assessment tests. Scand J Rheumatol Suppl 1987;65:85-9.

6. Lequesne $M$. Indices of severity and disease activity for osteoarthritis. Semin Arthritis Rheum 1991;20:48-54.

7. Lequesne MG. The algofunctional indices for hip and knee osteoarthritis. J Rheumatol 1997;24:779-81.

8. Newman JS, Laing TJ, McCarthy CJ, Adler RS. Power Doppler sonography of synovitis: assessment of therapeutic response-preliminary observations. Radiology 1996;198:582-4. 